\title{
An Enhanced Particle Method for Simulation of Fluid Flow Interactions with Saturated Porous Media
}

\author{
Abbas KHAYYER ${ }^{1}$, Hitoshi GOTOH ${ }^{2}$, Yuma SHIMIZU ${ }^{3}$, \\ Kohji GOTOH ${ }^{4}$ and Songdong $\mathrm{SHAO}^{5}$

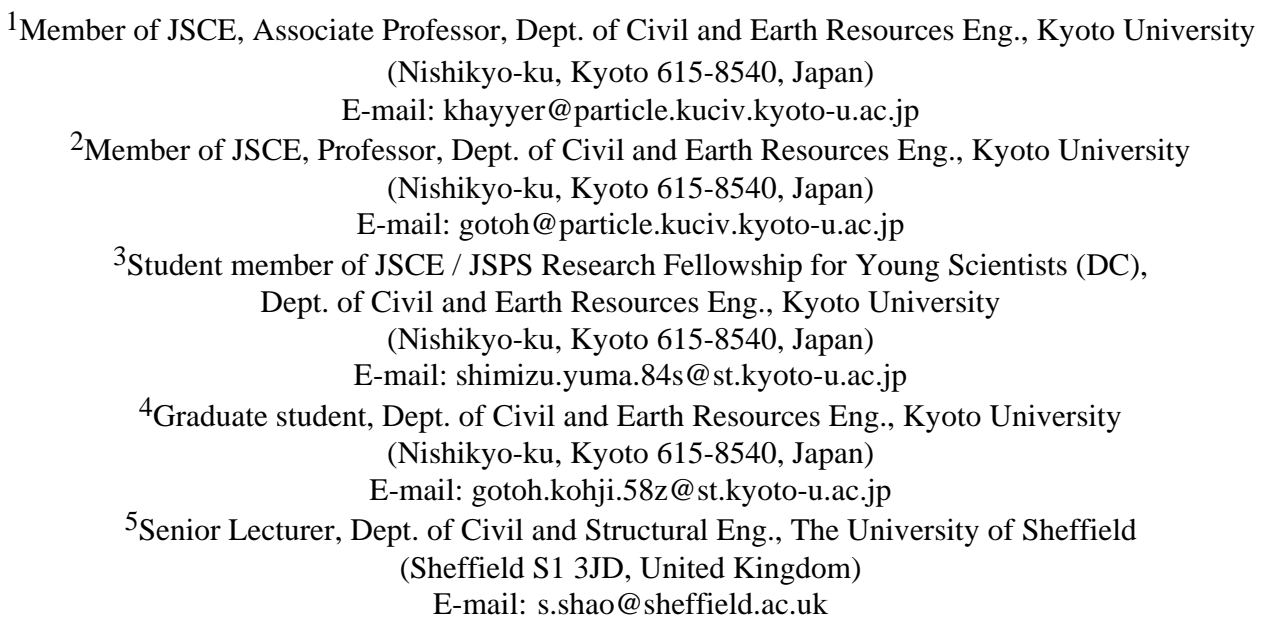

A novel numerical method is developed for simulation of fluid flow interactions with saturated porous media. The method is based on an enhanced version of Incompressible SPH (Smoothed Particle Hydrodynamics) method that solves Navier-Stokes and continuity equations and the effect of porous media is simply represented by considering linear and nonlinear resistance force terms similar to the studies by Ren et al. (2014) or Gui et al. (2015). However, one major difference is that in contrast to previous studies, in the developed method there is no numerical smoothing interface zone, thanks to the implemented enhanced schemes. The numerical method is validated through a set of benchmark tests, namely, flow in a U-tube with porous media (Peng et al., 2017), solitary wave attenuation over a porous bed (Gui et al., 2015) and solitary wave interaction with a submerged porous structure (Wu and Hsiao, 2013).

Key Words : Porous media, particle method, Smoothed Particle Hydrodynamics, incompressible flow, projection method

\section{INTODUCTION}

Porous media are substantial components in coastal infrastructures, such as porous seabed or submerged breakwaters. In order to assess the reliability and functionality of these structures, achievement of an in-depth understanding of characteristics of porous media, particularly in terms of wave interaction and consequent reflection /dissipation properties, is of significant importance in coastal engineering. On the other hand, several challenges arise in computational modelings of coastal waves interacting with porous media due to complex nature of violent waves as well as topological complexities of porous media. In view of these intrinsic challenges, Lagrangian meshfree methods, or particle methods, appear to be appropriate candidates for computational modeling of such important phenomena in view of their potential robustness and flexibility.

In this paper, a novel, enhanced particle method is presented to simulate fluid flow interactions with porous media. The solver is based on Incompressible SPH (ISPH) method $^{1)}$, providing the solutions to governing equations for incompressible fluid flow, corresponding to continuity and Navier-Stokes equations. The effects of porous media are included by solving governing equations inside of the porous media and by considering linear and nonlinear resistance force terms in the momentum equation, 
similar to those in the studies by Ren et al. ${ }^{2)}$ and Gui et al. ${ }^{3)}$. However, one major difference is that in contrast to previous studies, in our developed method there is no numerical smoothing interface zone, thanks to the implemented enhanced schemes, proposed to provide consistent and accurate numerical solutions to governing equations in the framework of projection-based particle methods. It should be noted that the focused porous media are deliberately considered to be fully-saturated with water in order to have a simple and reliable mathematical formulation of the problem.

Section 2 describes the numerical model. Then in section 3 , the proposed numerical method is validated through a set of benchmark tests, namely, flow in a U-tube with porous media ${ }^{4)}$, solitary wave attenuation over a porous bed ${ }^{3)}$ and solitary wave interaction with a submerged porous structure ${ }^{5)}$.

\section{NUMERICAL MODEL}

\section{(1) Governing equations}

In general, the governing equations comprise of the continuity and the Navier-Stokes equations, described as follows:

$$
\begin{gathered}
\frac{D \rho}{D t}+\rho \nabla \cdot \boldsymbol{u}_{w}=0 \\
\frac{D \boldsymbol{u}_{w}}{D t}=-\frac{1}{\rho} \nabla p+\boldsymbol{g}+v \nabla^{2} \boldsymbol{u}_{w}
\end{gathered}
$$

where $\rho$ is the density, $\boldsymbol{u}_{w}$ represents the velocity for a particle outside of the porous media, $p$ stands for pressure, $v$ represents kinematic viscosity and $\boldsymbol{g}$ denotes gravitational acceleration vector.

The governing equations inside the porous media are modified as follows ${ }^{6}$ :

$$
\begin{gathered}
\frac{D \rho}{D t}+\rho \nabla \cdot \boldsymbol{u}_{d}=0 \\
S \frac{D \boldsymbol{u}_{d}}{D t}=-\frac{1}{\rho} \nabla p+\boldsymbol{g}+\frac{\boldsymbol{R}}{\rho} \\
S=\left\{\frac{1+\left(1-n_{w}\right) C_{m}}{n_{w}}\right\}
\end{gathered}
$$

where $\boldsymbol{u}_{d}$ represents the Darcy velocity, $n_{w}$ signifies porosity of the porous media, $\boldsymbol{R}$ denotes the resistant force from porous media and $C_{m}$ is a coefficient of added mass. In this study, the following resistant force model $^{7,8)}$ is applied.

$$
\begin{gathered}
\frac{\boldsymbol{R}}{\rho}=-\frac{v}{K_{p}} \boldsymbol{u}_{d}-\frac{C_{f}}{\sqrt{K_{p}}} \boldsymbol{u}_{d}\left|\mathbf{u}_{d}\right| \\
K_{p}=1.643 \times 10^{-7}\left[\frac{D_{50}}{D_{0}}\right]^{1.57} \frac{n_{w}^{3}}{\left(1-n_{w}\right)^{2}} \\
C_{f}=100\left[D_{50}\left(\frac{n_{w}}{K_{p}}\right)^{0.5}\right]^{-1.5}
\end{gathered}
$$

where $D_{50}$ stands for mean diameter and $D_{0}=0.01 \mathrm{~m}$.

\section{(2) Enhanced schemes}

The numerical simulations are carried out in the framework of ISPH method ${ }^{1)}$ and through implementation of a set of previously proposed and broadly validated enhanced schemes, namely, Corrected Incompressible SPH (CISPH), Higher-order Source term of PPE (HS), Higher-order Laplacian model (HL), Error Compensating Source term of PPE (ECS), Gradient Correction (GC) and Dynamic Stabilization (DS). A $5^{\text {th }}$ order Wendland kernel is chosen as the kernel function throughout the simulations. Detailed information on the mentioned schemes can be found in recent papers by Khayyer et al. ${ }^{9)}$ as well as Gotoh and Khayyer ${ }^{10)}$. The mentioned schemes have been shown to enhance the accuracy, consistency and conservation properties of the enhanced ISPH method.

\section{VERIFICATION}

The numerical method is validated through a set of benchmark tests, namely, flow in a U-tube with porous media ${ }^{4}$, solitary wave attenuation over a porous bed $^{3)}$ and solitary wave interaction with a submerged porous structure ${ }^{5)}$.

\section{(1) U-tube with porous media}

The first benchmark for verification of the developed numerical method corresponds to a U-tube with porous media representing a Darcy seepage problem. The porosity and the mean grain diameter are equal to $n_{w}=0.4$ and $D_{50}=0.03504 \mathrm{~m}$, respectively. The particles are $5.0 \mathrm{E}-2 \mathrm{~m}$ in diameter $\left(d_{0}=5.0 \mathrm{E}-2 \mathrm{~m}\right)$. The calculation time step is set according to CFL stability condition and a maximum allowable time step of $\Delta t_{\max }=2.0 \mathrm{E}-4 \mathrm{~s}$. In this simulation, the permeability, $K_{p}$, is obtained from the following equation:

$$
K_{h}=\frac{\rho g K_{p}}{\mu}
$$



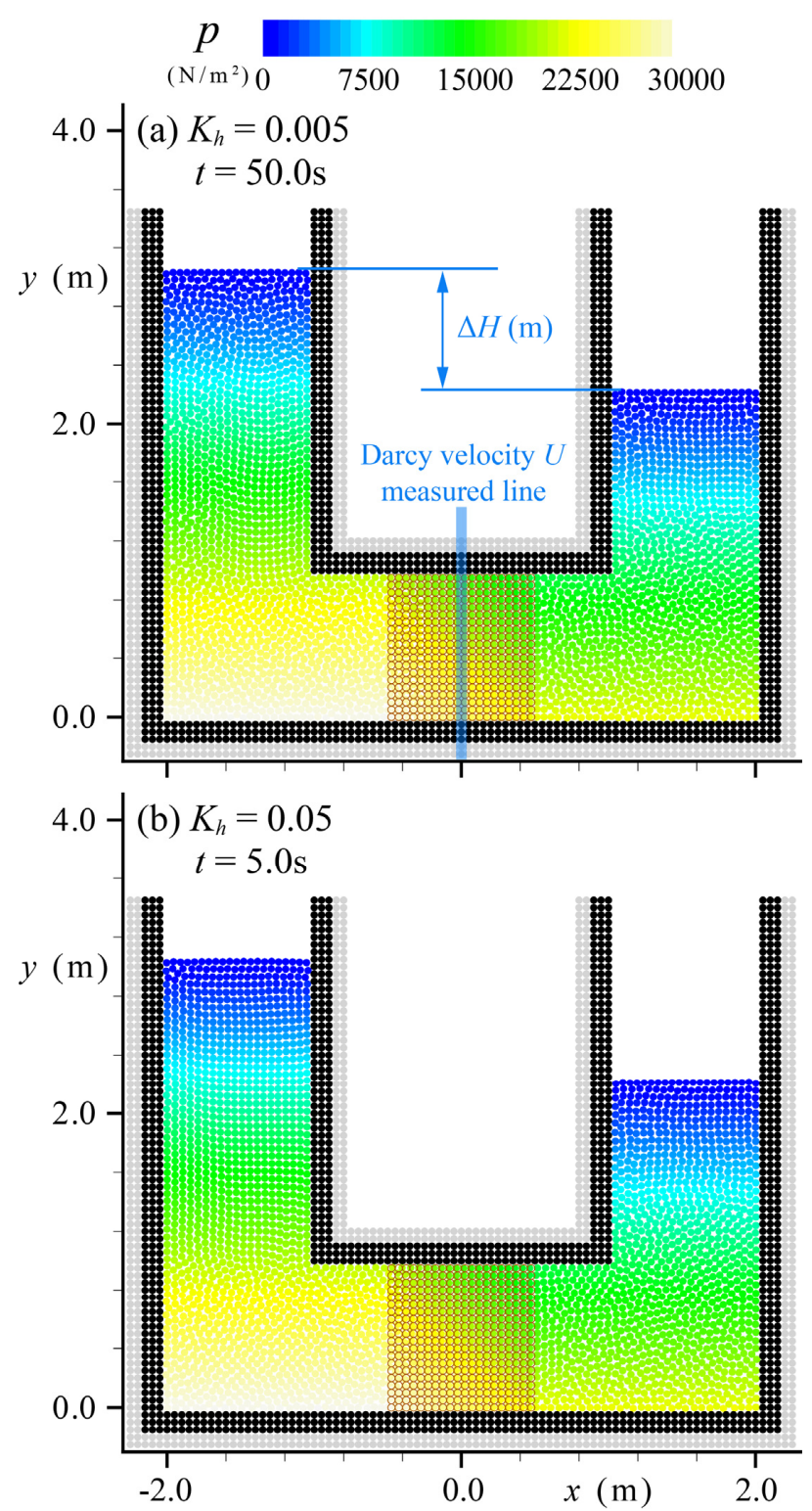

Fig. 1 Snapshots of particles together with pressure field (a) at $t=$ $50.0 \mathrm{~s}$ for $K_{h}=0.005$ and (b) at $t=5.0 \mathrm{~s}$ for $K_{h}=0.05-$ U-tube with porous media ${ }^{4}$

where $K_{h}$ signifies hydraulic conductivity, which is set as $0.05,0.01,0.005$ and 0.001 in order to assess the accuracy of proposed method.

Fig. 1 illustrates typical snapshots of particles together with pressure fields at (a) $t=50.0 \mathrm{~s}$ for $K_{h}=$ 0.005 and (b) $t=5.0 \mathrm{~s}$ for $K_{h}=0.05$. From the presented figure, the Enhanced ISPH provides smooth and continuous pressure field at the porous media interfaces regardless of the considered permeability.

Figs. 2(a) and (b) present a quantitative comparison in between simulation results and analytical solutions in terms of time variations of water level differences, $\Delta H$, and Darcy velocity, $U$, in the soil at $x=0.0 \mathrm{~m}$. The analytical solutions are derived on the basis of assumption of Darcy seepage condition and are formulated as follows ${ }^{4}$ :

\begin{tabular}{|l}
$\circ$ Enhanced ISPH $\left(K_{h}=0.050\right)-$ Analytical $\left(K_{h}=0.050\right)$ \\
$\circ$ Enhanced ISPH $\left(K_{h}=0.005\right)-$ Analytical $\left(K_{h}=0.005\right)$ \\
$\circ$ Enhanced ISPH $\left(K_{h}=0.010\right)-$ Analytical $\left(K_{h}=0.010\right)$ \\
$\circ$ Enhanced ISPH $\left(K_{h}=0.001\right)-$ Analytical $\left(K_{h}=0.001\right)$
\end{tabular}
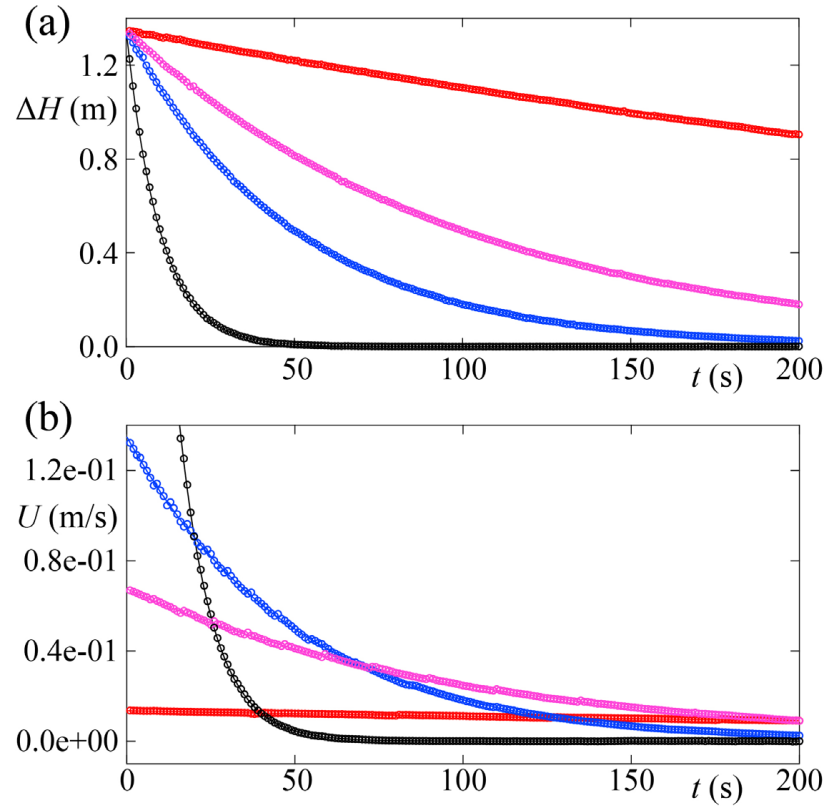

Fig. 2 Time variations of (a) water level differences and (b) Darcy velocity in the soil at $x=0.0 \mathrm{~m}$ for different hydraulic conductivities $\left(K_{h}\right)$ - U-tube with porous media ${ }^{4}$

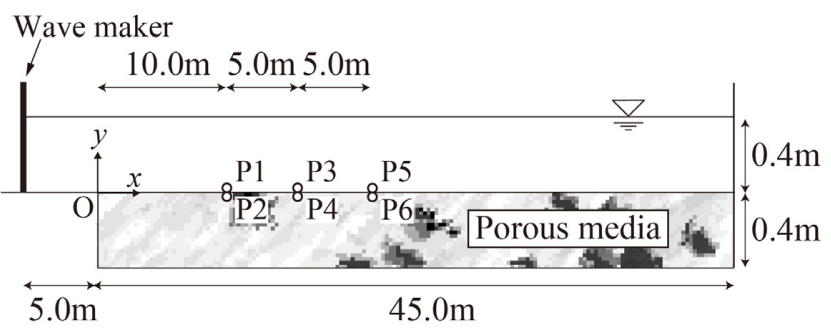

Fig. 3 Schematic sketch of computational domain - solitary wave attenuation over a porous bed ${ }^{3)}$

$$
\begin{gathered}
\Delta H=\frac{\Delta H_{0}}{\exp \left(2 K_{h} t / L\right)} \\
U=\frac{\Delta H_{0} K_{h}}{\exp \left(2 K_{h} t / L\right) L}
\end{gathered}
$$

where $L$ signifies the seepage path length (= $1.0 \mathrm{~m}$ ) and $\Delta H_{0}$ indicates the initial water level difference (= $1.35 \mathrm{~m}$ ). Figs. 1 and $\mathbf{2}$ portray the high accuracy of proposed method in reproducing a Darcy seepage problem as all simulation results are in good agreements with their corresponding analytical solutions.

\section{(2) Solitary wave attenuation over a porous bed}

The second benchmark test corresponds to a solitary wave attenuation over a porous bed. The computational domain is schematically illustrated in Fig. 3. A solitary wave, generated by a wave maker, 


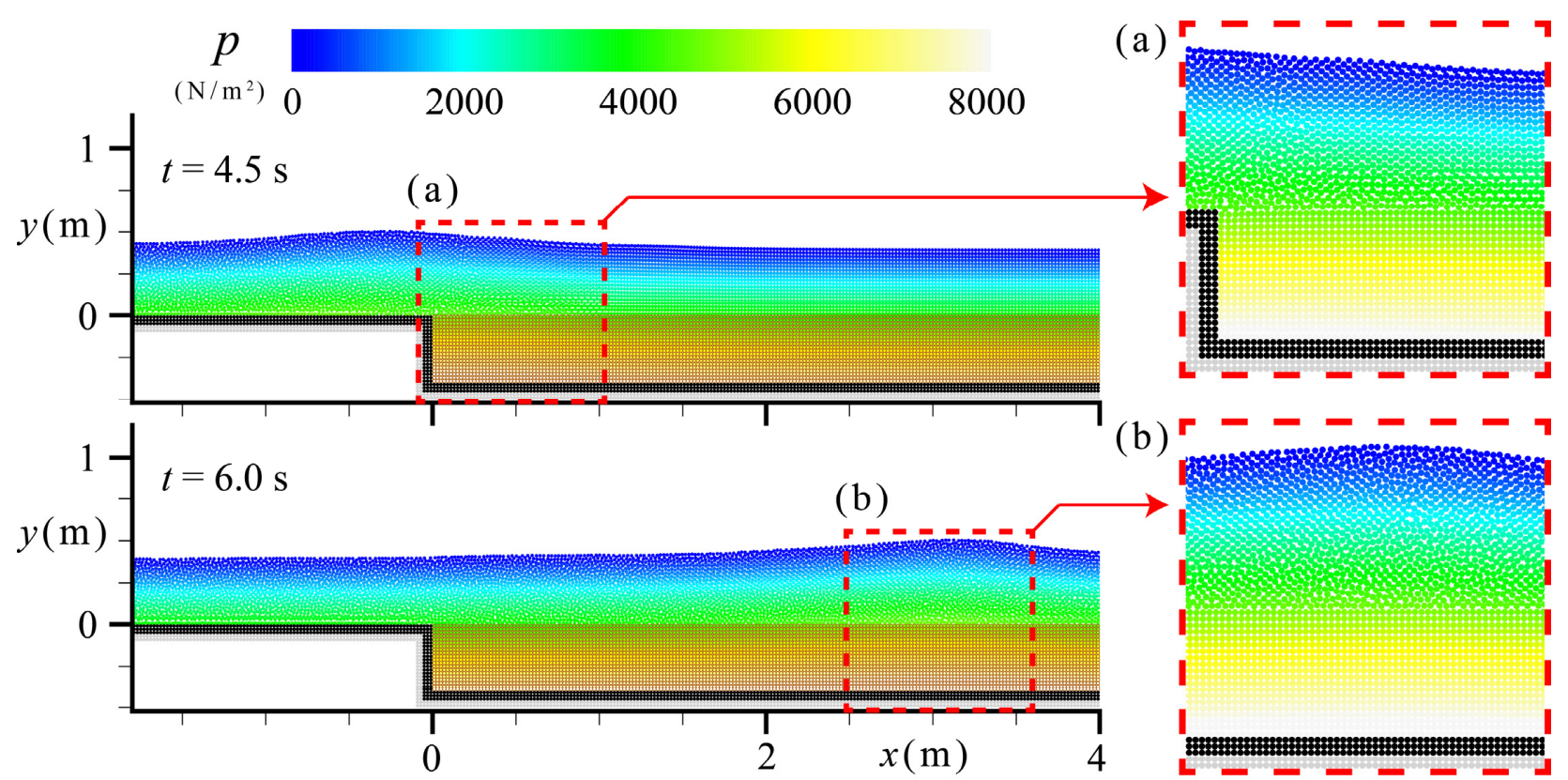

Fig. 4 Typical snapshots illustrating the pressure field at $t=4.5 \mathrm{~s}$ and $t=6.0 \mathrm{~s}-$ solitary wave attenuation over a porous bed ${ }^{3)}$

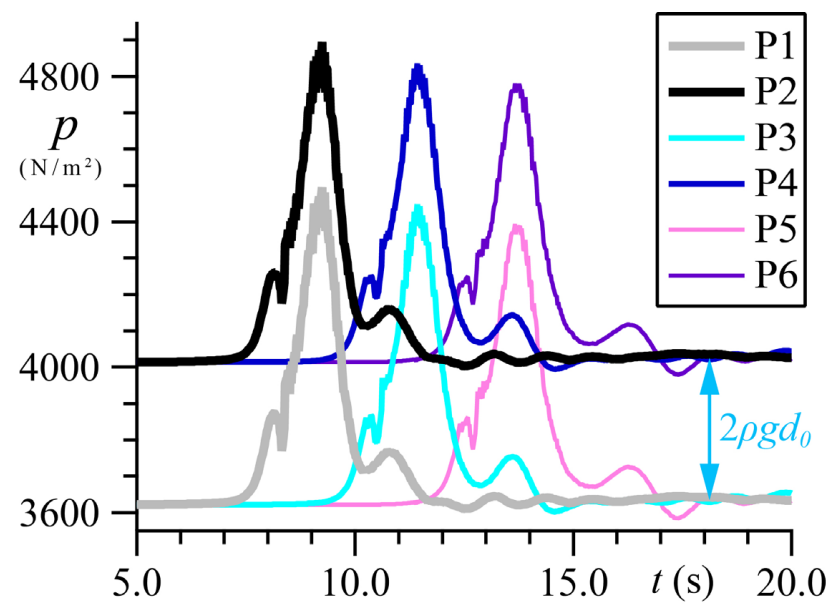

Fig. 5 Time histories of pressure at six measuring points P1 to P6 - solitary wave attenuation over a porous bed ${ }^{3)}$

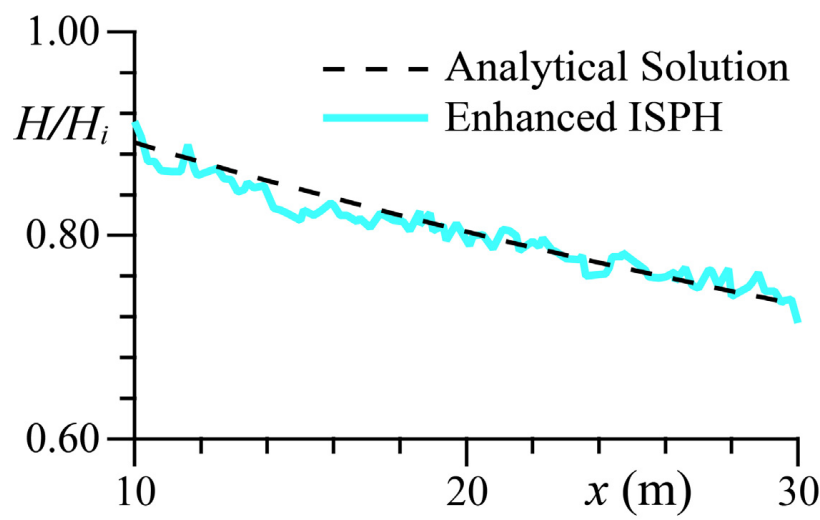

Fig. 6 Attenuation of wave height over a porous bed - solitary wave attenuation over a porous bed ${ }^{3)}$

propagates over the porous bed and results will be assessed in terms of continuity of pressure at the fluid-porous media interface as well as wave height attenuation. The incident wave height, $H_{i}$, is set as
$0.11 \mathrm{~m}$. The porosity and the mean grain diameter are set equal to $n_{w}=0.39$ and $D_{50}=0.055 \mathrm{~m}$, respectively. The particles are $2.0 \mathrm{E}-2 \mathrm{~m}$ in diameter $\left(d_{0}=\right.$ $2.0 \mathrm{E}-2 \mathrm{~m}$ ). The maximum allowable time step size is set as $\Delta t_{\max }=2.0 \mathrm{E}-3 \mathrm{~s}$.

Fig. 4 portrays two snapshots of particles together with pressure field at $t=4.5 \mathrm{~s}$ and $t=6.0 \mathrm{~s}$. The figure illustrates the continuity of pressure at fluid-porous media interface without implementation of any special numerical treatment, such as a numerical interface zone.

Fig. 5 shows the time histories of pressure at six measuring points corresponding to P1 to P6 in Fig. 3. P1, P3 and P5 are located one diameter above the interface while P2, P4 and P6 are placed one diameter below it. The figure shows that the pressure differences are consistent to a hydrostatic pressure difference and thus verifies the pressure continuity at the interface quantitatively.

In Fig. 6, the wave height attenuation is compared with the theoretical damping function by Packwood and Peregrine ${ }^{11)}$, showing that the Enhanced ISPH has also provided an almost accurate prediction of wave height attenuation over the porous bed. The damping function is described as follows:

$$
\begin{gathered}
H=\frac{H_{i}}{1+C_{s}\left(H_{i} / h_{0}\right)\left(x / h_{0}\right)} \\
C_{s}=0.4\left(K_{h} / C_{0}\right)\left(h_{p} / h_{0}\right) \\
C_{0}=\sqrt{g h_{0}}\left(1+H_{i} / 2 h_{0}\right)
\end{gathered}
$$

where $H_{i}$ denotes incident wave height, $h_{p}$ stands for depth of porous bed and $h_{0}$ signifies the water depth. 


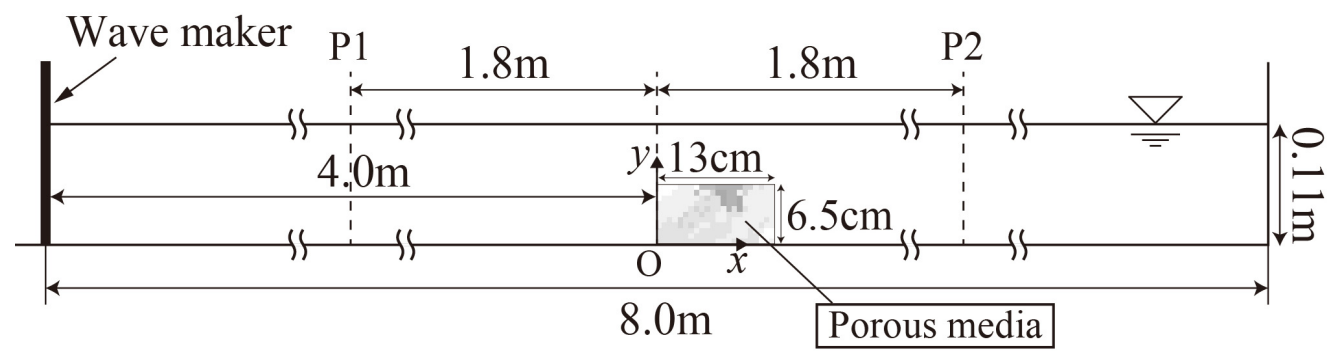

Fig. 7 Schematic sketch of computational domain - solitary wave interaction with a submerged porous structure ${ }^{5)}$

\section{(3) Solitary wave interaction with a submerged porous structure}

The third benchmark corresponds to a solitary wave interaction with a submerged porous structure corresponding to the experiment by $\mathrm{Wu}$ and Hsiao $(2013)^{5)}$. Fig. 7 presents a schematic sketch of the computational domain. A solitary wave generated by a paddle-type wave maker ${ }^{12)}$ propagates over the submerged porous structure. Here, the incident wave height is set as $0.0477 \mathrm{~m}$. The porosity and the mean grain diameter of the porous structure are set equal to $n_{w}=0.52$ and $D_{50}=0.015 \mathrm{~m}$, respectively. The particles are $5.3 \mathrm{E}-3 \mathrm{~m}$ in diameter $\left(d_{0}=5.3 \mathrm{E}-3 \mathrm{~m}\right)$ and the maximum allowable time step size is set $\Delta t_{\max }=$ 5.0E-4 s.

Fig. 8 presents a set of snapshots of particles together with pressure field at $t=1.39 \mathrm{~s}, t=1.77 \mathrm{~s}$ and $t=2.15 \mathrm{~s}$. The figure highlights the pressure continuity at the fluid-porous media interface and also depicts the vortical structures on right hand side of porous media. It should be noted here that $t=0.0 \mathrm{~s}$ corresponds to the instant at which the solitary wave crest reaches $x=-1.8 \mathrm{~m}$. Fig. 9 presents a simulation-experiment comparison of wave heights at $x=$ $-1.8 \mathrm{~m}$ and $x=1.8 \mathrm{~m}$, illustrating the accuracy of developed method quantitatively.

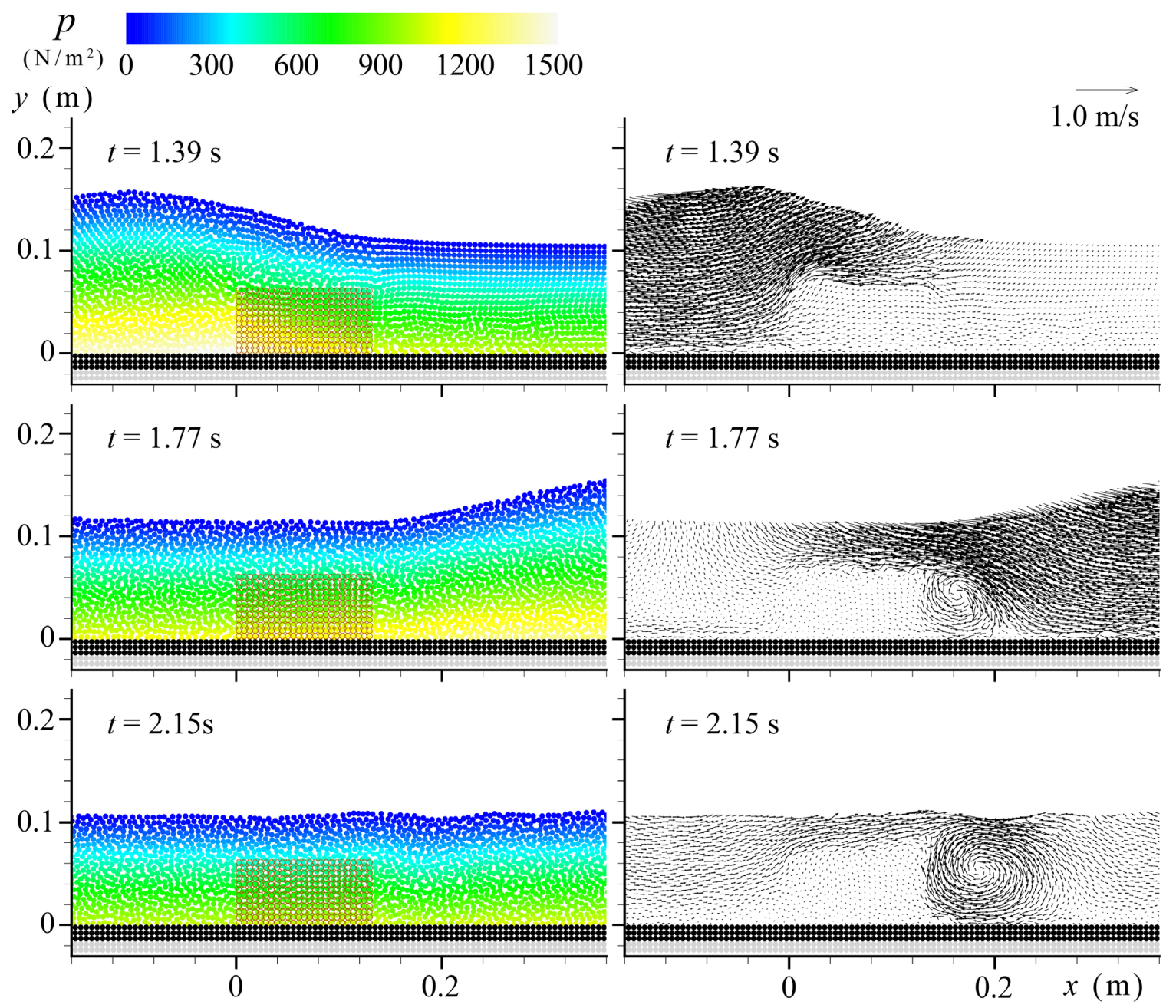

Fig. 8 Typical snapshots illustrating the pressure and velocity fields at $t=1.39 \mathrm{~s}, t=1.77 \mathrm{~s}$ and $t=2.15 \mathrm{~s}-$ solitary wave interaction with a submerged porous structure ${ }^{5)}$ 


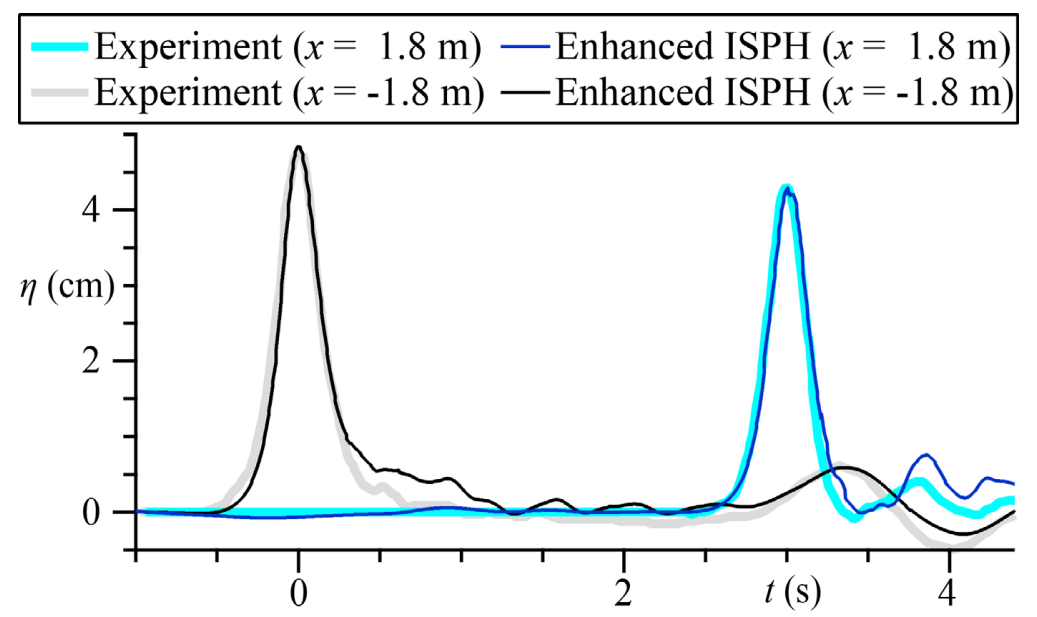

Fig. 9 Comparison of wave heights at $x=-1.8 \mathrm{~m}$ and $x=1.8 \mathrm{~m}$ - solitary wave interaction with a submerged porous structure ${ }^{5)}$

\section{CONCLUDING REMARKS}

The paper presents a novel ISPH-based numerical method to simulate fluid flow interactions with saturated porous media. The method solves $\mathrm{Na}$ vier-Stokes and continuity equations and the effect of porous media is simply represented by considering linear and nonlinear resistance force terms similar to the studies by Ren et al. ${ }^{2)}$ or Gui et al. ${ }^{3)}$. However, one major difference is that in contrast to previous studies, in our proposed method there is no numerical smoothing interface zone, thanks to the implemented enhanced schemes, proposed to provide consistent and accurate numerical solutions to governing equations in the framework of projection-based particle methods. Indeed, consideration of a numerical interface zone, implemented by spatial velocity/pressure averaging adversely affects the overall accuracy and conservation properties of numerical method.

The proposed numerical method is validated through a set of benchmark tests, namely, flow in a U-tube with porous media ${ }^{4}$, solitary wave attenuation over a porous bed ${ }^{3)}$ and solitary wave interaction with a submerged porous structure ${ }^{5)}$. The method is shown to possess a high level of accuracy and guarantees the volume and pressure continuity at the fluid-porous media interface.

Future works comprise of further numerical validations, convergence studies, further applications to coastal engineering-related problems, extensions to unsaturated porous media as well as variable porosity, and consideration of turbulence modeling, for instance, by incorporation of SPS ${ }^{13)}$ (Sub-Particle-Scale) turbulence model.

\section{REFERENCES}

1) Shao, S. and Lo, E.Y.M. : Incompressible SPH method for simulating Newtonian and non-Newtonian flows with a free surface, Advances in Water Resources, Vol. 26(7), pp.
787-800, 2003.

2) Ren, B., Wen, H., Dong, P. and Wang, Y. : Numerical simulation of wave interaction with porous structures using an improved smoothed particle hydrodynamic method, Coastal Engineering, Vol. 88, pp. 88-100, 2014.

3) Gui, Q., Dong, P., Shao, S. and Chen, Y. : Incompressible SPH simulation of wave interaction with porous structure, Ocean Engineering, Vol. 110, pp. 126-139, 2015.

4) Peng, C., Xu, G., Wu, W., Yu, H.S. and Wang, C. : Multiphase SPH modeling of free surface flow in porous media with variable porosity, Computers and Geotechnics, Vol. 81, pp. 239-248, 2017.

5) Wu, Y.-T. and Hsiao, S. C. : Propagation of solitary waves over a submerged permeable breakwater, Coastal Engineering, Vol. 81, pp. 1-18, 2013.

6) Losada, I.J., Lara, J.L. and del Jesus, M. : Modeling the Interaction of Water Waves with Porous Coastal Structures, Journal of Waterway Port Coastal and Ocean Engineering, Vol. 142(6), 03116003, 2016.

7) Sollitt, C. K. and Cross, R. H. : Wave transmission through permeable breakwaters, Proc. 13th Coastal Eng. Conf., ASCE, pp. 1864-1872, 1972.

8) Huang, C.J., Chang, H.H., Hwung, H.H. : Structural permeability effects on the interaction of a solitary wave and a submerged breakwater, Coast. Eng., Vol 49, 1-24, 2003.

9) Khayyer, A., Gotoh, H., Shimizu, Y. and Gotoh, K. : On enhancement of energy conservation properties of projection-based particle methods, in press, European Journal of Mechanics - B/Fluids, DOI: 10.1016/j.euromechflu. 2017.01.014.

10) Gotoh, H. and Khayyer, A. : Current achievements and future perspectives for projection-based particle methods with applications in ocean engineering, Journal of Ocean Engineering and Marine Energy, Vol. 2(3), pp. 251-278, 2016.

11) Packwood, A. R. and Peregrine, D. H. : The propagation of solitary waves and bores over a porous bed, Coastal engineering, Vol. 3, pp. 221-242, 1979.

12) Khayyer, A., Gotoh, H. and Shao, S.D. : Corrected Incompressible SPH method for accurate water-surface tracking in breaking waves, Coastal Engineering, Vol. 55(3), pp. 236-250, 2008.

13) Gotoh, H., Shibahara, T. and Sakai, T. : Sub-Particle-Scale turbulence model for the MPS method - Lagrangian flow model for hydraulic engineering -, Computational Fluid Dynamics J., Vol. 9(4), pp. 339-347, 2001.

(Received March 15, 2017) 